Staff Working Paper/Document de travail du personnel 2019-6

\title{
The Distributional Effects of Conventional Monetary Policy and Quantitative Easing: Evidence from an Estimated DSGE Model
}

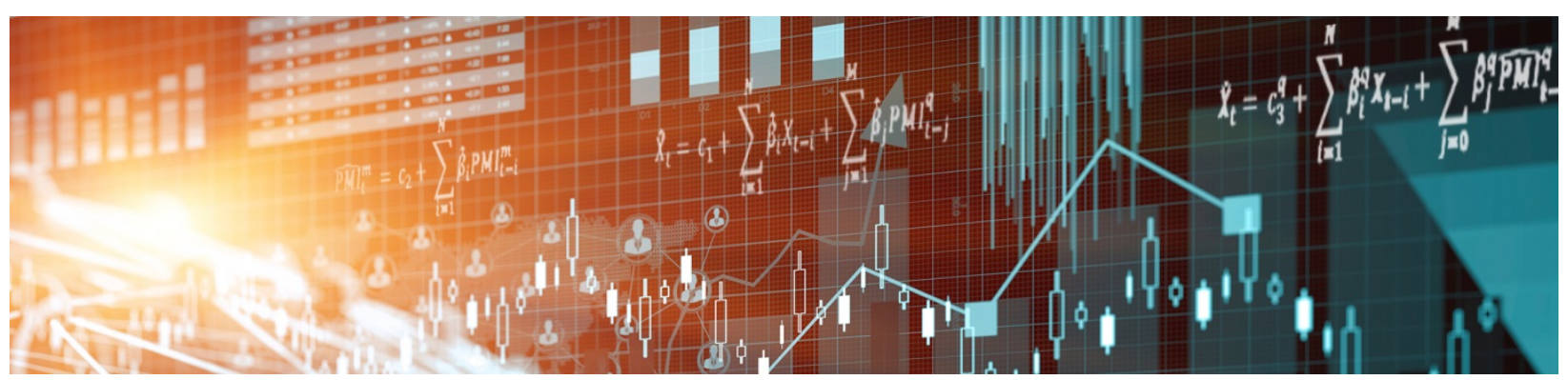

by Stefan Hohberger, Romanos Priftis and Lukas Vogel 
Bank of Canada Staff Working Paper 2019-6

January 2019

\title{
The Distributional Effects of Conventional Monetary Policy and Quantitative Easing: Evidence from an Estimated DSGE Model
}

\author{
by \\ Stefan Hohberger, ${ }^{1}$ Romanos Priftis ${ }^{2}$ and Lukas Vogel ${ }^{3}$ \\ 1 European Commission, Joint Research Centre \\ ${ }^{2}$ Canadian Economic Analysis Department \\ Bank of Canada \\ Ottawa, Ontario, Canada K1A OG9 \\ rpriftis@bankofcanada.ca \\ ${ }^{3}$ European Commission, DG ECFIN
}




\section{Acknowledgements}

We thank Gert Bekaert, Fabian Eser, Stefano Gnocchi, Claudia Godbout, Massimo Giovannini, Richard Harrison, Serdar Kabaca, Rigas Oikonomou, Beatrice Pataracchia, Marco Ratto, Werner Roeger, and Mary Veronica Tovšak Pleterski for helpful comments on this and previous versions of the paper. We also thank seminar participants at the Université Catholique de Louvain, the Bank of Canada, the 14th Annual EEFS Conference, the 47th MMF Research Group Annual Conference, the 6th IWH/INFER Workshop on (Ending) Unconventional Monetary Policy, the $1^{\text {st }}$ CEPR Conference on Macro-Modelling and Model Comparison, the $21^{\text {st }}$ International Conference on Macroeconomic Analysis and International Finance, the 2017 Annual Meeting of the German Economic Association, the 2017 European Winter Meeting of the Econometric Society, and XENOPHON 2017. The views expressed are those of the authors and should not be attributed to the Bank of Canada or the European Commission. 


\begin{abstract}
This paper compares the distributional effects of conventional monetary policy and quantitative easing $(\mathrm{QE})$ within an estimated open-economy DSGE model of the euro area. The model includes two groups of households: (i) wealthier households, who own financial assets and can smooth consumption over time, and (ii) poorer households, who only receive labor and transfer income and live "hand to mouth." We compare the impact of policy shocks on constructed measures of income and wealth inequality (net disposable income, net asset position, and relative per-capita income). Except for the short term, expansionary conventional policy and QE shocks tend to mitigate income and wealth inequality between the two population groups.
\end{abstract}

Bank topics: Economic models; Interest rates; Monetary policy; Transmission of monetary policy

JEL codes: E44, E52, E53, F41

\title{
Résumé
}

Dans cette étude, nous comparons les effets redistributifs des mesures de politique monétaire traditionnelles et des assouplissements quantitatifs dans le cadre d'un modèle d'équilibre général dynamique et stochastique en économie ouverte estimé pour la zone euro. Notre modèle comprend deux groupes de ménages : d'une part, des ménages riches, c'est-à-dire qui possèdent des actifs financiers et qui peuvent lisser leur consommation dans le temps, et, d'autre part, des ménages plus pauvres, qui ne reçoivent que des revenus du travail et de transfert et qui vivent au jour le jour. Nous comparons l'incidence que des chocs de politique monétaire peuvent avoir sur diverses mesures des inégalités de revenu et de richesse (revenu disponible net, actif net et revenu relatif par habitant). Les chocs liés à des mesures de politique monétaire traditionnelles expansionnistes ou à des assouplissements quantitatifs tendent à atténuer les inégalités de revenu et de richesse entre les groupes considérés, excepté à court terme.

Sujets : Modèles économiques; Taux d'intérêt; Politique monétaire; Transmission de la politique monétaire

Codes JEL : E44, E52, E53, F41 


\section{Non-technical summary}

In the context of persistent income and wealth inequality, distributional effects of economic policy occupy a prominent place in policy discussions these days. This is true particularly for structural policies and for fiscal measures, which often have an explicit redistributive aspect. In the aftermath of the financial crisis, however, the distributional implications of monetary policy have likewise received more attention.

In this paper, we investigate and contrast the distributional effects of conventional monetary policy and quantitative easing $(\mathrm{QE})$. As proposed by the literature, $\mathrm{QE}$ may reduce income inequality by stimulating economic activity, similar to conventional monetary policy. However, it may also increase inequality by boosting asset prices. The goal of our analysis is to quantify the relative strength of these opposing forces and determine their overall effect on income and wealth inequality.

To this end, we build on Hohberger, Priftis, and Vogel (2018) and develop a general equilibrium model that distinguishes between two types of households: (i) wealthy "financial investors" that hold financial assets and receive related income in addition to wages and transfers, and (ii) poorer "asset-less" households that only receive wage and transfer income. Then we examine the impact of conventional monetary policy and QE shocks on selected measures of income and wealth inequality (e.g., disposable income shares, net asset positions, and a model-consistent version of the Gini coefficient) at different horizons. The model features most of the transmission channels discussed in the literature, such as those related to heterogeneity in income and portfolio composition, financial segmentation, and elements of the savings redistribution channel.

Our analysis suggests that, similar to conventional short-term interest rate cuts, expansionary QE measures do not have permanent effects on income and wealth inequality. However, the QE policy shock tends to increase income inequality in the short run, while income and wealth inequality are mitigated over the medium term.

The results are primarily driven by the impact of unconventional monetary policy shocks on financial asset prices and portfolio composition. Expansionary unconventional monetary policy boosts asset prices on impact and favors asset holders at the expense of poorer liquidity-constrained households, exacerbating income inequality in the short run. On the other hand, central bank asset purchases depress wealthy households' long-term bond holdings and returns, mitigating income and wealth inequality over the medium term. 


\section{Introduction}

In the context of persistent, or even increasing, income and wealth inequality, distributional effects of economic policy occupy a prominent place in policy discussions these days. This is true particularly for structural policies and for fiscal measures, which often have an explicit redistributive aspect. In the context and aftermath of the financial crisis, however, the distributional implications of monetary policy have likewise received more attention.

In the context of non-standard measures, the link between quantitative easing $(\mathrm{QE})$ and asset prices has nurtured the view that QE has predominantly benefited wealthy asset owners. Although this property is certainly present, a more thorough analysis should also include other effects of QE, notably its stabilizing impact on economic activity, employment, and wage income, which remains a central motivation behind the policy.

In this paper, we investigate and contrast the distributional effects of two monetary policy regimes in a general equilibrium framework: (i) conventional monetary policy, where the central bank follows a Taylor rule targeting inflation and the output gap, and (ii) QE, where the central bank expands its balance sheet by purchasing long-term government bonds from the private sector. Our analysis builds on the estimated DSGE model of Hohberger et al. (2018), which introduces elements to study the macroeconomic implications of the European Central Bank's (ECB's) quantitative easing policies.

The model distinguishes between two types of households: (i) "financial investors" that hold assets (government bonds, firm equity, and foreign bonds) and receive related income in addition to wages and transfers, and (ii) "asset-less" households that only receive wage and transfer income. Financial investors can smooth disposable income and consumption over time through financial markets, i.e., they do not face liquidity constraints (NLC). Asset-less households live hand-tomouth, i.e., they face binding liquidity constraints (LC).

We compare the distributional effects of the two forms of monetary policy by studying the impulse responses of a number of constructed measures capturing income and wealth inequality: the net disposable income, the net asset positions (financial wealth), and the per-capita net disposable income relative to the population average. Given the model's focus on asset-holding versus hand-tomouth households, the analysis concentrates on the impact of monetary policy on different func- 
tional income groups (labor income versus asset returns) instead of a more disaggregated perspective on heterogeneity in portfolio holding and associated portfolio valuation and investment income effects.

The literature has investigated the effect of monetary policy on aggregate economic variables, including total output, employment, and inflation, widely and for many decades. In contrast, the theoretical and empirical literature investigating the distributional effects of monetary policy is relatively new. A large share of the existing assessments adopts a partial equilibrium view, notably regressions of inequality metrics on monetary policy indicators that control for factors that may themselves depend on monetary policy in the shorter or longer term. Moreover, the empirical analyses face the difficulty that non-standard policies have been in place for a much shorter period of time, so that time series for longer horizons and larger country samples are not yet readily available.

Accounting for interactions between different parts of the economy in establishing the net effects of monetary policy over different time horizons is the strength of structural dynamic macroeconomic models. There exists some work in this regard focusing on conventional policy, e.g., Gornemann et al. (2016), who analyze the distributional consequences of conventional monetary policy in a New Keynesian model with household heterogeneity in time preferences and skills. Their analysis finds that monetary policy, which explicitly targets employment stabilization, helps "ordinary" households, but hurts asset owners by reducing precautionary savings, and generating more volatile inflation. In turn, this lowers the payout of dividends and hence asset prices. Our paper, to the best of our knowledge, is the first to focus on relative income and wealth effects of QE in comparison to conventional monetary policy in an estimated DSGE framework.

The early New Keynesian DSGE models built on the assumption of a representative household, which precluded income or wealth inequality in the household sector. Subsequent work has introduced forms of heterogeneity, notably along the dimensions of wealth endowment and access to financial markets, to better match business cycle facts. Liquidity-constrained consumers (e.g., Galí et al. 2007) and credit-constrained households (e.g., Iacoviello 2005) are prominent examples. More recently, heterogeneous-agent New Keyensian (HANK) models (e.g., Kaplan et al. 2018) have introduced richer income and wealth distributions. At present, accounting for a richer income and wealth distribution comes with constraints on the complexity in other dimensions and on the possibility to estimate the model, however.

In light of the trade-off between a richer income and wealth distribution (HANK models), on the one hand, and additional complexity in other dimensions (notably the distinction between bonds of 
different maturity, the open economy setup with international trade and financial integration, and model estimation), on the other hand, we use a two-agent New Keynesian (TANK) model. This setup can be thought of as a tractable middle ground between the traditional (one) representativeagent New Keynesian framework and the HANK model of, e.g., Kaplan et al. (2018). Our framework makes two simplifying assumptions compared to HANK models. First, the population shares of the different (two) households are constant, i.e., invariant to shocks. Second, we abstract from idiosyncratic income risk, which eliminates precautionary saving motives. Recent work by Debortoli and Gali (2018) shows that, despite these differences, the aggregate transmission of a monetary policy shock in TANK models is similar to that in a comparable HANK setup. The hand-to-mouth (LC) household with labor and transfer income approximates income dynamics for the poorer part, whereas intertemporally optimizing bond and equity holders represent the wealthier share of the population.

We model QE as a public-sector asset purchase program, which has been the dominant form of unconventional monetary policy in the euro area (EA), by incorporating a central bank balance sheet and distinguishing between short-term and long-term government debt. We use a formulation of private-sector portfolio composition, which breaks neutrality of central bank balance sheet policies by introducing imperfect substitutability between assets of different maturity (as in, e.g., Andrés et al. 2004; Priftis and Vogel 2016). The approach is similar to the "preferred habitat" investor framework of Vayanos and Vila (2009), who provide a theoretical model for a duration risk channel of QE. The "preferred habitat" model incorporates two agents: one has preferences for assets of a particular maturity, generating a downward sloping demand curve for that asset; the second agent is an arbitrageur, investing in all assets. In equilibrium, changes in the supply of an asset of a particular maturity affect the price of that asset, and, by arbitrage, also the prices of other assets. QE thus reduces the duration risk in the hands of investors and alters the yield curve. Neely (2015) shows that a portfolio choice model can reproduce observed changes in US and foreign bond yields and the USD exchange rate in the context of US QE. Moreover, Greenwood and Vayanos (2014) show empirically how the supply and maturity structure of government debt can affect bond yields and expected returns.

In our framework, the central bank expands its balance sheet by purchasing long-term bonds from the private sector. In response, prices of (imperfectly substitutable) short-term bonds, corporate equity, and foreign-currency-denominated assets increase, yielding a reduction in household savings, a reduction in firm financing costs, and exchange rate depreciation. 
The analysis in this paper suggests that, similar to conventional monetary policy, expansionary QE measures do not increase income and wealth inequality between the two population groups in our model persistently. Conventional and unconventional (QE) expansionary monetary policy shocks have a similar impact on real GDP, inflation, employment, and the real exchange rate. In both cases, the wage share falls on impact, as wage stickiness raises firm profits, before it returns to baseline and positive territory in the medium term. The net income share of hand-to-mouth (LC) households falls on impact, due to the decline in the wage share and the increase in firm profits. In the medium term, when wages catch up, the income share of the LC households, who are the poorer part of the population, increases to above baseline. The income share of asset owners (NLC), as a mirror image, declines in response to expansionary monetary shocks in our model. The decline is more pronounced and more persistent for the QE shock, which follows from the reduction in private-sector long-term bond holdings and associated returns. Looking at the relative per-capita disposable income also indicates a (moderate) decline in income inequality in response to expansionary policy shocks.

The net asset position of wealthy asset holders increases on impact in our two scenarios, as lower interest rates are associated with an increase in the value of bonds (valuation effects). In the medium term, QE reduces the net asset position of NLC households. The wealth decumulation relative to baseline follows from the shrinking of the household's holding of interest-bearing long-term bonds and the reduction in private-sector savings for a protracted period.

Our paper is related to the recent theoretical and empirical literature analyzing the distributional effects of both conventional and unconventional monetary policy. As mentioned above, a large part of these studies adopts a partial equilibrium perspective in which feedback effects that arise from monetary policy in general equilibrium cannot be captured to the same extent as in a dynamic macroeconomic model. In addition, given that QE policies have been implemented only more recently and more sporadically, empirical analysis of their distributional properties has to rely on short time series and selected country samples.

Regarding conventional policy, Coibion et al. (2017) find that contractionary monetary policy in the US increases labor and total income inequality. Furceri et al. (2018) find analogously that expansionary conventional policy reduces income inequality in a panel of 32 countries. Domanski et al. (2016) use simulations of household finance surveys from five European countries and the US and find that changes in wealth inequality since 2009 are driven by movements in equity and house prices. House price increases alone tend to reduce inequality, whereas increases in equity prices 
tend to increase wealth inequality. Similarly, O'Farrell et al. (2017) stress the uneven distribution of asset classes across the wealth distribution, so that distributional effects at the household or individual level depend on which types of asset prices change most. Adam and Tzamourani (2016) use the Household Finance and Consumption Survey to show that the effect of asset price inflation on wealth inequality in EA countries varies across assets. Growth in bond prices does not have significant effects, increases in equity prices increase wealth inequality, and increases in house prices reduce wealth inequality.

Regarding unconventional monetary policy, Montecino and Epstein (2015) use data from the Federal Reserve's Survey of Consumer Finances and find that recent expansionary unconventional monetary policy in the US contributed to rising income inequality. Equity price appreciation and declines in real wages (despite large increases in employment levels) more than offset the equalizing impact stemming from mortgage refinancing. Using detailed micro-level data, Mumtaz and Theophilopoulou (2017) arrive at similar results for the Bank of England's QE measures. Saiki and Frost (2014) estimate a VAR with household survey data and find that the expansionary nonstandard monetary policy in Japan has widened income inequality in the late 2000 s, due to asset price increases that benefit primarily upper income households.

Focusing on the EA, Guerello (2018) estimates a panel VAR with monetary policy indicators and measures of income inequality. Her results suggest high cross-country heterogeneity in the impact of monetary policy and interactions with the redistributive strength of fiscal policy and the maturity of the household portfolio. She finds that unconventional monetary policy tends to increase income inequality the more wealth is stored in financial assets rather than deposits. Redistributive fiscal policy can mitigate or offset the impact on net income, however. Casiraghi et al. (2018) use the Banca d'Italia quarterly model to simulate monetary policy impulses on a micro dataset of Italian households' income and wealth. They find that the recent unconventional monetary policy measures of the ECB have produced a negligible effect on inequality in Italy.

Related to the results in this paper, Ampudia et al. (2018) assess the impact of standard and nonstandard monetary policy on inequality in the EA based on household survey data and find expansionary monetary policy reduces income inequality. Expansionary policy hurts households with significant liquid assets by reducing their income from wealth. More importantly still, expansionary monetary policy raises labor income, which benefits worker households without significant wealth. The increase in labor income of hand-to-mouth workers has also reduced consumption inequality in the EA. This has occurred despite the observation by Dolado et al. (2018), based on 
US data, that expansionary monetary policy may raise income inequality among workers by increasing the wage premium for highly skilled workers.

The remainder of the paper is structured as follows: Section 2 outlines the elements of the model specific to the analysis of QE and the distributional effects of monetary policy. Section 3 describes the model solution and estimation methodology. Section 4 discusses the impact of conventional policy and QE shocks on the economy and the income and wealth distribution. Section 5 summarizes the paper and concludes.

\section{Model environment}

Our analysis is undertaken in the two-region (EA and rest-of-the-world (RoW)) model of Hohberger et al. (2018), which introduces elements to study the effects of QE using the portfolio rebalancing approach. We motivate non-neutrality of QE through the imperfect substitutability between long-term and short-term government bonds as in, e.g., Andrés et al. (2004), Chen et al. (2012), Harrison (2012), and Priftis and Vogel (2016).

The EA region in the model is a one-sector economy. Perfectly competitive firms produce the final good, combining domestic and foreign intermediate goods and (imported) energy inputs. Firms in the intermediate goods sector are monopolistically competitive and maximize the present value of dividends (at a discount factor larger than the risk-free rate). There are two types of households: NLC households, who hold financial assets (equity and bonds), and LC households, who have no financial wealth and live "hand-to-mouth." Given the holding of corporate equity (generating dividends) and domestic and foreign bonds (generating interest income), NLC households are significantly income-richer than LC ones in the steady state of our model. NLC households use financial markets to insure against income volatility, while LC households cannot insure and therefore benefit more strongly from a stabilization of economic activity and wage income. Wages of households are set by monopolistic trade unions. The government levies taxes on consumption, labor, profits, and a lump-sum tax, and issues debt to finance expenditures on consumption, investment, and transfers. The model features a number of nominal and real frictions (prices, wages, labor, and capital adjustment), which are important to match business cycle properties.

In view of the limitation to focusing on NLC versus LC households, our model lends itself to an analysis of income inequality based on labor income and asset returns (as well as redistribution through fiscal policy) rather than an assessment of wealth inequality. Regarding the latter, any 
increase (decline) in value of the NLC asset position implies an increase (decline) in wealth inequality, given that LC households have zero financial wealth.

In what follows, we outline the elements of the model that are specific to the investigation of the distributional effects of conventional monetary policy and QE. ${ }^{1}$

\subsection{Distributional effects of monetary policy}

The literature has discussed a number of channels through which monetary policy may affect inequality. ${ }^{2}$ Our model captures the following elements: The income composition channel is present insofar as the two types of households have distinct income sources, and income from these sources varies in response to monetary policy. The portfolio channel is present, as expansionary monetary policy tends to increase the value of bonds and equity held by asset owners. The model also includes the counteracting effect that higher inflation in response to expansionary policy lowers the real value of nominal wealth. There are elements of the savings redistribution channel. ${ }^{3}$ Notably, exchange rate adjustment affects the real value of the net foreign asset position and the associated interest payments; inflation affects the real value of government debt, where interest income goes to asset owners, whereas tax liabilities affect all households. The model also features a form of the financial segmentation channel in that the LC households do not have access to financial markets. ${ }^{4}$ Notably, our model does not capture an earnings heterogeneity channel (e.g., through sectoral or skill differentiation) as wage and employment levels are the same for the two groups of households.

\subsection{NLC households}

The estimated value for the share of NLC households in our model (0.82) is in line with survey evidence in Ampudia et al. (2018) that $77 \%$ of EA households have significant liquid assets, and can hence reallocate portfolios. Kaplan et al. (2014) report quantitatively similar population shares for the remainder of LC households for a number of Western countries, namely approximately $20 \%$ for the US, approximately $20 \%$ or less for Australia, France, Italy, and Spain, and approximately $30 \%$ for Canada, the UK, and Germany.

\footnotetext{
${ }^{1}$ The outline neglects shocks and adjustment costs that are not crucial for the description. For a detailed overview of the model see Hohberger et al. (2018).

${ }^{2}$ For a discussion of the main distributional channels of monetary policy see Coibion et al. (2017).

${ }^{3}$ As there is no direct borrower-lender relationship between hand-to-mouth households and asset holders, there is no direct redistribution between domestic private debtors and lenders, which is otherwise a key element of the savings redistribution channel (Doepke and Schneider 2006).

${ }^{4}$ Williamson (2009) discusses a stricter form of the financial segmentation channel distinguishing between different classes of financial investors.
} 
NLC households' preferences are given by the infinite horizon expected life-time utility:

$$
U=E_{0} \sum_{t=0}^{\infty} \tilde{\beta}_{t} u_{t}(.)
$$

with $\tilde{\beta}_{t}=\beta \exp \left(\varepsilon_{t-1}^{C}\right)$, where $\beta$ is the (non-stochastic) discount factor and $\varepsilon_{t}^{C}$ captures a shock to the subjective rate of time preference (saving shock). They enjoy utility from consumption, $C_{t}^{N L C}$, and incur disutility from labor, $N_{t}^{N L C}$. The instantaneous utility function of NLC households is defined as:

$$
u\left(C_{t}^{N L C}, N_{t}^{N L C}\right)=\frac{1}{1-\theta}\left(C_{t}^{N L C}-h C_{t-1}^{N L C}\right)^{1-\theta}-\frac{\omega^{N}}{1+\theta^{N}}\left(C_{t}\right)^{1-\theta}\left(N_{t}^{N L C}\right)^{1+\theta^{N}}
$$

where $h \in(0 ; 1)$ measures the strength of external habits in consumption, and $\omega^{N}$ is the weight of the disutility of labor.

The real period $t$ budget constraint of NLC households, expressed relative to GDP deflator $P_{t}$, is:

$$
\begin{gathered}
\frac{\left(1+\tau^{C}\right) P_{t}^{C}}{P_{t}} C_{t}^{N L C}+\frac{B_{t}^{S}}{\omega\left(1+i_{t}\right) P_{t}}+\frac{P_{t}^{N} B_{t}^{L, H}}{\omega P_{t}}\left(1+\frac{\gamma_{b}}{2}\left(\kappa \frac{B_{t}^{S}}{B_{t}^{L, H}}-1\right)^{2}\right)+\frac{e_{t} B_{t}^{W}}{\omega\left(1+i_{t}^{W}\right) P_{t}}+\frac{\gamma_{f}}{2}\left(\frac{e_{t}\left(B_{t}^{W}-\bar{B}^{W}\right)}{P_{t} Y_{t}}\right)^{2}+ \\
\frac{P_{t}^{S} S_{t}}{\omega P_{t}}+\frac{T A X_{t}^{N L C}}{P_{t}}=\left(1-\tau^{N}\right) \frac{W_{t}}{P_{t}} N_{t}^{N L C}+\frac{B_{t-1}^{S}}{\omega P_{t}}+\frac{c+\delta_{b} P_{t}^{N}}{\omega P_{t}} B_{t-1}^{L, H}+\frac{e_{t} B_{t-1}^{W}}{\omega P_{t}}+\left(\frac{P_{t}^{S}+d_{t} P_{t}}{\omega P_{t}}\right) \frac{S_{t-1}}{\omega}+\frac{T R_{t}^{N L C}}{P_{t}}
\end{gathered}
$$

NLC households consume, $C_{t}^{N L C}$, invest in short-term government bonds, $B_{t}^{S}$, and long-term government bonds, $B_{t}^{L, H}$, foreign bonds, $B_{t}^{W}$, corporate shares, $S_{t}$, and pay taxes on consumption, labor income, and in a lump-sum way $\left(\tau^{C}, \tau^{N}\right.$, and $\left.T A X_{t}^{N L C}\right)$, repsectively. ${ }^{5}$ They receive labor income, $W_{t} N_{t}^{N L C}$, coupon payments on long-term bonds, $c$ (defined below), dividends on corporate shares, $d_{t}$, and interest income on short-term bonds, $i_{t}$, and foreign bonds, $i_{t}^{W}$, which are the differences between the notional value and the price at issuance. $e_{t} B_{t}^{W} /\left(1+i_{t}^{W}\right)$ is the price in domestic currency of a foreign bond, where $e_{t}$ is the nominal exchange rate as the value in domestic currency of one unit of foreign currency. NLC households face an adjustment cost of holding foreign bonds, $\gamma_{f}$, which captures a debt-dependent risk premium on foreign assets to ensure long-run stability (see Schmitt-Grohé and Uribe 2003). $P_{t}^{C}$ is the price of the consumption good. The dividends paid by intermediate good firms to shareholders are $d_{t}=\left(1-\tau^{K}\right)\left(Y_{t}-\frac{W_{t}}{P_{t}} N_{t}\right)+\tau^{K} \delta_{k} \frac{P_{t}^{I}}{P_{t}} K_{t-1}-$ $\frac{P_{t}^{I}}{P_{t}} I_{t}-a d j_{t}^{k}$, which is after-tax corporate $\operatorname{profit}\left(\tau^{K}\right)$, i.e., turnover minus wage costs plus the capital depreciation allowance, net of investment expenditure $\left(P_{t}^{I} I_{t}\right)$ and capital-stock adjustment costs

\footnotetext{
${ }^{5}$ We divide the value of financial assets by the population share of NLC households, $\omega$, to transform economy-wide per-capita values into values per NLC household member.
} 
$\left(\operatorname{adj}_{t}^{k}\right)$. The gross nominal return on equity $\left(1+i_{t}^{S}\right)$ can be defined as the combination of dividend payments and the change in share value, i.e., $1+i_{t}^{S}=\left(P_{t}^{S}+d_{t} P_{t}^{Y}\right) / P_{t-1}^{S}$.

\subsection{Imperfect substitutability between short-term and long-term bonds}

The total outstanding government debt consists of long-term bonds, $B_{t}^{L}$, held by the private sector, $B_{t}^{L, H}$, and the central bank, $B_{t}^{L, C B}$, and short-term bonds, $B_{t}^{S}$. The price in period $t$ of a short-term (1-period) bond of nominal value, $B_{t}^{S}$, is $B_{t}^{S} /\left(1+i_{t}\right)$, with $i_{t}$ being the short-term nominal interest rate. Long-term government debt is modeled as in Woodford (2001) as perpetuity that pays a nominal coupon, $c$, which depreciates every period at the rate $\delta_{b}$. The price in period $t$ of a long-term bond, $P_{t}^{N}$, issued in $t$ equals the discounted value of future payments, $P_{t}^{N}=\sum_{n=0}^{T} \frac{\delta_{b}^{n}}{(1+i)^{1+n}} c$, where $T$ is the maturity period of the bond. Short-term and long-term bonds are imperfect substitutes. In particular, NLC households target a mix of short-term and long-term bonds. Deviations from the target, $\kappa$, for the ratio of long-term to short-term debt induce quadratic adjustment costs, $\gamma_{b}$.

\subsection{Portfolio rebalancing}

NLC households maximize the present value of the expected stream of future utility subject to their budget constraint by choosing the amount of consumption, $C_{t}^{N L C}$, and next-period asset holdings, $B_{t}^{S}, B_{t}^{L, H}, S_{t}, B_{t}^{W}$. Combining the first-order conditions (FOCs) with respect to $B_{t}^{S}$ with $C_{t}^{N L C}, S_{t}$, and $B_{t}^{W}$, illustrates the transmission channels of monetary policy to the real economy in the model:

$$
\begin{aligned}
& \frac{1}{1+i_{t}}+\gamma_{b} \kappa P_{t}^{N}\left(\kappa \frac{B_{t}^{S}}{B_{t}^{L, H}}-1\right)=\beta E_{t}\left(\frac{\left(1+\tau^{C}\right) P_{t+1}^{C}}{\left(1+\tau^{C}\right) P_{t}^{C}} \frac{u^{\prime}\left(C_{t}^{N L C}\right)}{u^{\prime}\left(C_{t+1}^{N L C}\right)}\right) \\
& \frac{1}{1+i_{t}}+\gamma_{b} \kappa P_{t}^{N}\left(\kappa \frac{B_{t}^{S}}{B_{t}^{L, H}}-1\right)=E_{t}\left(\frac{P_{t}^{S}}{P_{t+1}^{S}+d_{t+1} P_{t+1}}\right) \\
& \frac{1}{1+i_{t}}+\gamma_{b} \kappa P_{t}^{N}\left(\kappa \frac{B_{t}^{S}}{B_{t}^{L, H}}-1\right)=E_{t}\left(\frac{e_{t}}{e_{t+1}}\left(\frac{1}{1+i_{t}^{W}}+\gamma_{f} e_{t} \frac{B_{t}^{W}-\bar{B}^{W}}{P_{t} Y_{t}}\right)\right)
\end{aligned}
$$

The effects of a conventional monetary policy shock work in a standard fashion through the direct impact that the change in the short-term interest rate has on macroeconomic variables. An expansionary monetary policy shock leads to a reduction in savings (eq. 4), an increase in the prices of corporate equity (eq. 5), and an increase in the demand for foreign-currency-denominated bonds, which leads to depreciation of the domestic currency (eq. 6). 
The impact of QE on asset prices derives from the NLC households' portfolio adjustment costs. If $\gamma_{b}>0$, the effects of falling $B_{t}^{L, H}$ relative to $B_{t}^{S}$ in the household portfolio, as the central bank purchases long-term bonds, are similar to the impact of a reduction of the short-term interest rate, $i_{t}$. Hence, QE can mimic the effects of a lower short-term interest rate on aggregate variables.

When the central bank purchases long-term bonds, NLC households, aiming to re-establish the portfolio mix of short-term and long-term bonds, can respond by investing in equity and foreign bonds and by reducing savings. For given levels of the short-term rate, QE reduces private saving (eq. 4), triggers portfolio reallocation from government bonds towards corporate equity (eq. 5), and leads to higher demand for foreign assets, which depreciates the domestic currency (eq. 6). Concerning the transmission to the real economy, (i) lower savings imply a substitution away from future consumption and towards contemporaneous consumption demand, (ii) rising stock markets lead to stronger investment and capital accumulation, and (iii) exchange rate depreciation strengthens net exports if export demand and import demand are sufficiently price elastic.

\subsection{Other channels of quantitative easing}

The impact of conventional expansionary monetary policy and QE on portfolio allocation in the model has implications for consumption and investment that are similar to those of an extension of credit. First, financial intermediaries may face a similar decision problem as NLC households in our setup. When the central bank buys long-term government bonds from banks, the latter can respond by buying more equity and foreign assets and by providing more loans to firms.

Second, expansionary monetary policy can raise the net worth of banks and extend their lending margin in the presence of capital-requirement or equivalent constraints, as in, e.g., Gertler and Karadi (2011). Notably, Ricci (2015) finds that banks are more sensitive to non-standard measures than to interest rate decisions.

Moreover, financial investors in our model can also be interpreted to include pension and investment funds that act on behalf of households. Boubaker et al. (2018) provides evidence for portfolio rebalancing among institutional investors in the form of a substantial increase in pension funds' allocation to equity assets during the US Fed's unconventional monetary policy measures.

Our framework abstracts from the risk-taking channel of monetary policy. The risk-taking channel argues that investment strategies of financial investors may involve a "search for yield" through a demand for risky, tail-risk sensitive, and illiquid securities (Rajan 2006; Borio and Zhu 2012) in a low interest rate environment (either through conventional policy or QE). The risk-taking channel 
of monetary policy has been shown to exist both in the US and in the EA. For the US, Bekaert et al. (2013) find a causal relationship between lax (conventional) monetary policy and increased risk appetite in financial markets. In addition, lower interest rates have been shown to result in reduced lending standards (Delis and Kouretas 2011; Maddaloni and Peydro 2011), higher leverage (de Groot 2014), as well as increased asset risks (Angeloni et al. 2015). For the EA, expansionary monetary policy is associated with an increase in the willingness of banks to accept risk (Altunbas et al. 2014; Jimenez et al. 2014) and with lower lending standards (Neuenkirch and Noeckel 2018).

The risk-taking channel constitutes an additional transmission mechanism for monetary policy, but its distributional implications for financial investors versus hand-to-mouth households are not obvious. While "search for yield" may imply higher asset returns and valuation effects, potentially beneficial effects on corporate investment, output, and employment would also benefit non-investor households through the labor income channel. Regarding distributional effects, the risk-taking channel may, hence, be similar to the portfolio rebalancing channel (combined with increased risk appetite), which we focus on in this paper.

Finally, an additional channel is that of investor sentiment (Lutz 2015), i.e., that expansionary monetary policy leads to increased investor confidence/sentiment. This channel is partially captured in our model as far as expansionary monetary policy is likely to improve the economic outlook, which in turn affects investment decisions by forward-looking agents.

\subsection{Conventional monetary policy and $Q E$ regimes}

Conventional monetary policy, as the first case, is described by a Taylor rule, where the central bank sets the short-term policy rate $i_{t}$ in response to inflation and the output gap. The policy rate reacts sluggishly to deviations of inflation from its respective target level and to the output gap, and it is subject to random shocks:

$$
i_{t}-\bar{\imath}=\rho^{i}\left(i_{t-1}-\bar{\imath}\right)+\left(1-\rho^{i}\right)\left(\eta^{i \pi}\left(0.25\left(\sum_{r=0}^{3} \pi_{t-r}^{c}\right)-\bar{\pi}^{c}\right)+\eta^{i y}\left(\tilde{y}_{t}\right)\right)+u_{t}^{i n o m}
$$

where $\bar{l}=r+\pi^{c}$ is the steady-state nominal interest rate, equal to the sum of the steady-state real interest rate and steady-state CPI inflation. $\tilde{y}_{t} \equiv \log \left(Y_{t}\right)-\bar{y}_{t}$ is the output gap with $\bar{y}_{t}$ as $(\log )$ potential output. It is assumed that the risk-free rate is equal to the policy rate. A monetary policy shock in the conventional setting is therefore a shock to the exogenous component of the Taylor rule, $u_{t}^{\text {inom }}$. 
$\mathrm{QE}$, as the second case, implies an increase in the central bank's holding of longer-maturity assets. In the context of the European public-sector purchase program (PSPP), which accounts for most of the ECB's QE measures since 2015, the central bank purchases long-term government bonds $\left(B_{t}^{L, C B}\right.$ ) and provides additional liquidity to the private sector. The operating profit of the central bank equals the sum of base money issuance and interest income minus the current expenditure on buying long-term bonds, where the latter equals the change of the value of long-term bonds on the central bank's balance sheet:

$$
P R_{t}^{C B}=\Delta M_{t}+c B_{t-1}^{L, C B}-\left(P_{t}^{N} B_{t}^{L, C B}-\delta_{b} P_{t}^{N} B_{t-1}^{L, C B}\right)
$$

We focus on the situation where the central bank engages in QE under an (endogenously) binding zero lower bound (ZLB) constraint. A binding ZLB implies that the target ("shadow") short-term policy rate is below the lower bound. An increase in output and inflation achieved by QE or other factors does not lead to tightening of the short-term rate as long as the ZLB is binding. As in Hohberger et al. (2018), we treat the occasionally binding ZLB via a piecewise linear solution. We employ the OccBin method developed by Guerrieri and Iacoviello (2015) and complement it with an algorithm by Giovannini and Ratto (2018) to obtain smoothed estimates of latent variables as well as the sequence of binding regimes along the historical sample.

In the case of conventional monetary policy, the endogenous part of the unconstrained nominal short-term interest rate $i_{t}^{N C}$ follows the Taylor rule in equation (7) without monetary shock $u_{t}^{\text {inom }}$. As long as the actual policy rate $\left(i_{t}\right)$ is above the lower bound, it can be expressed as:

$$
i_{t}=i_{t}^{N C}+u_{t}^{\text {inom }}
$$

If $i_{t}^{N C} \leq i^{L B}=0$, the policy rate is constrained:

$$
i_{t}=i^{L B}+u_{t}^{i n o m}
$$

The variable $i_{t}^{N C}$ acts as the "shadow" interest rate under a constrained regime. The algorithm by Giovannini and Ratto (2018) allows for determining endogenously the duration of an occasionally binding constraint (see Hohberger et al. 2018). 
In order to assess the distributional impact of monetary policy we construct measures of household income and wealth positions and trace the responses of these statistics to standard monetary policy and quantitative easing shocks.

Net disposable income of LC households: Net disposable income of the "hand-to-mouth" households is the sum of net wage income and transfer income minus lump-sum taxes:

$$
\left(1-\tau^{N}\right) W_{t} N_{t}^{L C}+T R_{t}^{L C}-T A X_{t}^{L C}
$$

Net disposable income of NLC households: Net disposable income of the asset owners is the sum of net wage income, interest income from short-term government bonds, coupon payments on longterm government bonds, interest income on the foreign-currency-denominated bonds, dividend income on equity, and transfer income minus lump-sum taxes:

$$
\left(1-\tau^{N}\right) W_{t} N_{t}^{L C}+\frac{i_{t}}{1+i_{t}} \frac{B_{t}^{S}}{\omega}+c \frac{B_{t-1}^{L, H}}{\omega}+\frac{i_{t}^{W}}{1+i_{t}^{W}} e_{t} \frac{B_{t}^{W}}{\omega}+d_{t} P_{t}^{Y} \frac{S_{t-1}}{\omega}+T R_{t}^{N L C}-T A X_{t}^{N L C}
$$

Net asset position of NLC households: The net asset position of asset holders at the beginning of period $t$ equals the value of holdings of short-term and long-term government bonds, net foreigncurrency-denominated bonds, corporate equity, and money:

$$
\frac{B_{t-1}^{S}}{\omega}+\delta_{b} P_{t}^{N} \frac{B_{t-1}^{L, H}}{\omega}+e_{t} \frac{B_{t-1}^{W}}{\omega}+P_{t}^{S} \frac{S_{t-1}}{\omega}+\frac{M_{t-1}}{\omega}
$$

When discussing income inequality (Section 4), we will emphasize the response of LC (NLC) disposable income relative to average disposable income in the economy. In the context of our twohousehold model, the relative per-capita income is a simpler metric than, e.g., the Gini coefficient, which measures the concentration of income or wealth along a continuum of heterogeneous households. Concerning the wealth distribution, as already mentioned, any increase (decline) in the value of the NLC household asset portfolio constitutes an increase (decline) in wealth inequality in our model, given that LC households have zero financial wealth.

\section{Econometric approach and model solution}

We compute an approximate model solution by linearizing the model around its deterministic steady state. We calibrate a subset of parameters to match long-run data properties and estimate the remaining parameters using Bayesian methods. The observables employed in estimation are listed in the Data Appendix. The estimation uses quarterly data for the period 1999q1-2017q1. We 
also perform estimation on the subsample 1999q1-2014q4 to test the stability of parameter estimates, especially the adjustment cost (portfolio preference) parameter $\gamma_{b}$, with respect to the implementation of QE. The model has been estimated using the slice sampler algorithm proposed by Neal (2003).

We calibrate the steady state of the model so that steady-state ratios of main economic aggregates (relative to GDP) match average historical ratios over the sample period (see Table B.1 in the Appendix). The EA steady-state ratios of private consumption and investment to GDP are set to $56 \%$ and $18 \%$, respectively. The steady-state share of EA GDP in world GDP is $16 \%$. The steadystate trade share $(0.5 *$ (exports + imports)/GDP) is set at $19 \%$ in the EA (excluding intra-EA trade), and the quarterly depreciation rate of capital is $1.4 \%$. We set the steady-state government debt to $74 \%$ of annual GDP in the EA. The steady-state real GDP growth and inflation rates are set to $0.35 \%$ and $0.4 \%$ per quarter, respectively, and the effective rate of time preferences to $0.25 \%$ per quarter.

With respect to the QE model extension, we observe the "securities held for monetary policy purposes" as proxy for long-term bond holdings by the ECB, the share of long-term debt in total government debt, and the current and 3-month-ahead swap rates on 10-year government bonds to calculate the implied expected period-on-period return on long-term bonds. ${ }^{6}$ We set the steady-state portfolio share of long-term to short-term government debt $(\kappa)$ to 0.916 in line with the average of outstanding EA government debt over the sample period. Since we use interest rates for bonds with residual maturity of 10 years in our quarterly model, the corresponding depreciation rate of longterm government debt $\left(\delta_{\mathrm{b}}\right)$ is 0.975 .

It is crucial to identify the parameter on portfolio adjustment costs $\left(\gamma_{b}\right)$ accurately as this parameter determines the impact of QE on the spread between short-term and long-term bond yields in the model. We specify a prior distribution with a mean of $15 / 10000$ and a standard deviation of $6 / 10000 .^{7}$ This captures the range of changes in interest spreads between short- and long-term bonds around the time of the ECB's QE announcement.

We treat ECB QE as an AR(2) shock for which the estimated parameters provide a hump-shaped path of central bank holdings of long-term government debt. The AR(2) specification captures the

\footnotetext{
6 This approach is consistent with our modeling assumption that agents are not obliged to hold long-term bonds to maturity, but can trade these bonds in the secondary market at each period in time instead.

${ }^{7}$ We check the robustness of this prior by specifying an uninformative uniform distribution for $\gamma_{\mathrm{b}}$. In both cases the posterior estimate is well identified around 0.0007 .
} 
expectation of a further expansion of the central bank balance sheet in the future, as announced by the ECB at the start of its PSPP.

For QE under the ZLB constraint, we calculate impulse response functions (IRFs) using the concept of generalized IRFs: We choose as a starting point 2015q1, which is a period of constrained monetary policy according to the Giovannini and Ratto (2018) algorithm, and the official start of the PSPP. We shut off the QE shock and simulate the model with all remaining shocks. Then we perform simulations adding a QE shock equivalent to long-term bond purchases of $1 \%$ of steady-state quarterly EA GDP on impact. The difference between the two simulations provides the IRF of the QE shock under an occasionally binding constraint. The size of the simulated QE shock is illustratively calibrated and does not reflect the actual purchases of long-term bonds by the ECB.

In order to render the aggregate effects of the conventional monetary policy shock comparable to those of the QE shock, we adjust the monetary policy rule to generate GDP effects that are comparable in magnitude and dynamics to the QE shock. Since the monetary policy shock is being estimated as a white noise shock, we harmonize the persistence of the policy paths by setting the interest rate smoothing parameter $\left(\rho^{i}\right)$ to 0.95 , which quantitatively mimics the short-run effects of the QE shock on GDP under a ZLB regime.

The posterior estimates of key model parameters for the EA are reported in Table B.2 in the Appendix. The posterior estimates are based on the linearized version of the model (without ZLB); they are also used for the solution with an occasionally binding constraint. 


\section{Distributional effects of monetary policy shocks}

Figure 1 shows responses of EA macro aggregates and relative income and wealth to a standard monetary policy and a QE shock. Figure 2 provides a decomposition of the components of NLC household income as described in Section 2.7. ${ }^{8}$

Figure 1: Impulse responses for expansionary short-term rate and QE shock
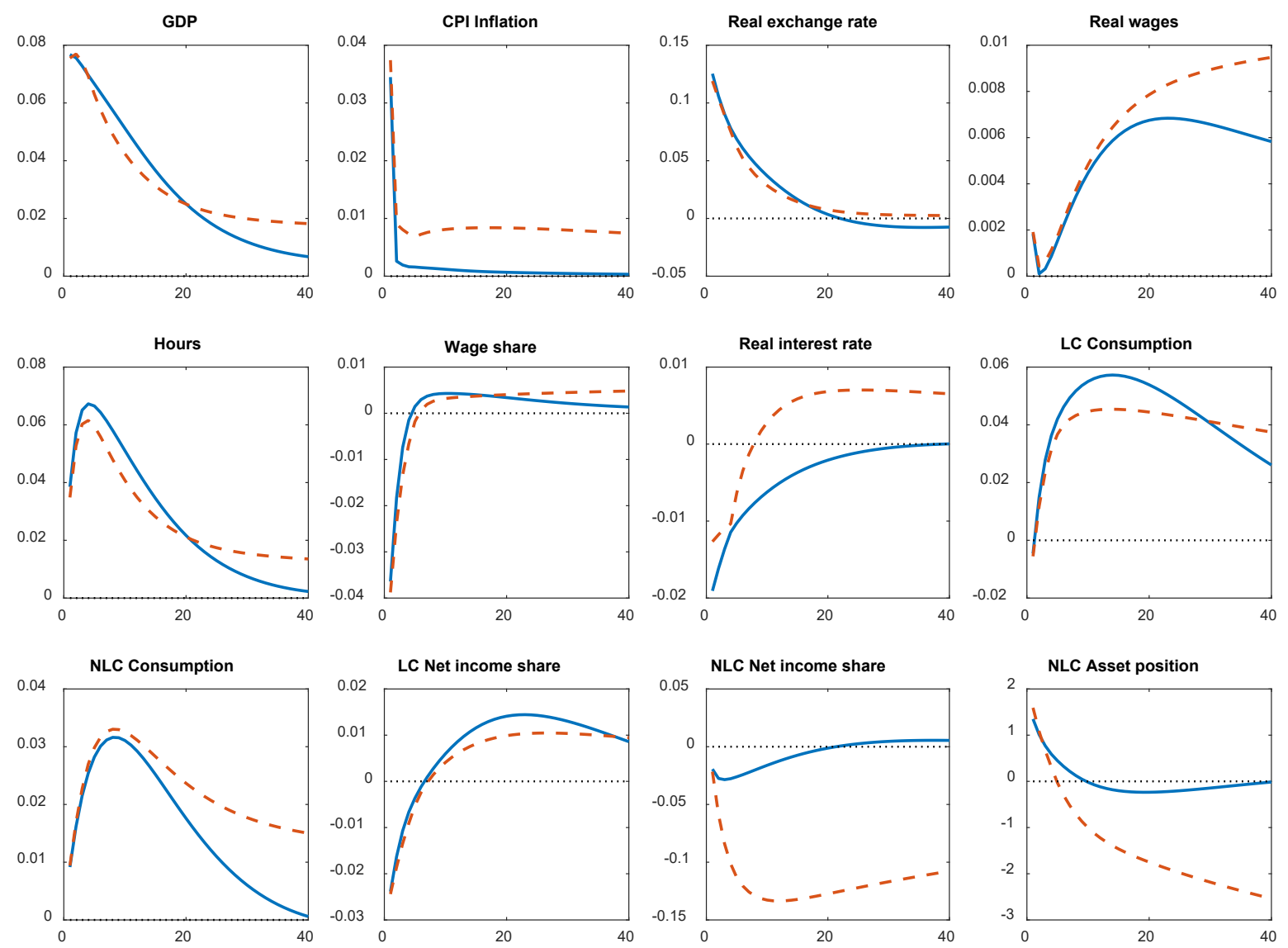

-- Quantitative easing with ZLB

Note: Time intervals on the x-axis are quarters; units on the y-axis are in per cent, except for inflation, interest rates, the wage share, income shares, and the net asset position (percentage points). The wage share, the income shares and the net asset position are expressed relative to quarterly nominal GDP.

${ }^{8}$ Across all Figures we do not report error bands accounting for estimation uncertainty, but note that all impulse response functions are statistically significant at the $95 \%$ confidence level. 
Figure 2: Decomposition of NLC net income into components
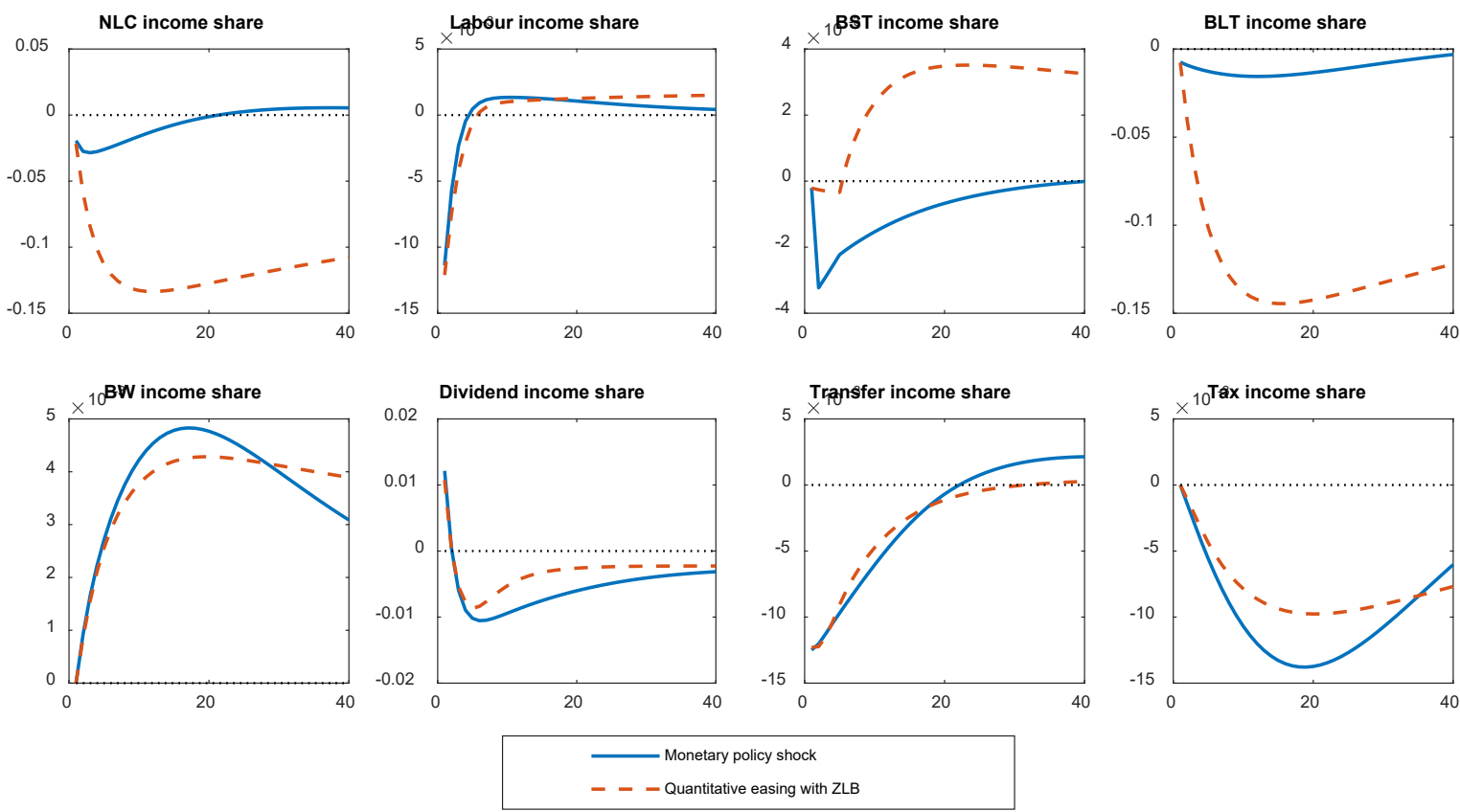

Note: Time intervals on the x-axis are quarters. The income shares are expressed relative to quarterly nominal GDP and displayed in percentage-point deviations from the baseline.

\subsection{Conventional monetary policy}

Following an expansionary conventional monetary policy shock, real GDP and inflation increase temporarily. The domestic currency depreciates in nominal terms, and the economy depreciates against the RoW also in real effective terms. Real wages and hours worked increase in response to growing demand for labor. The short-term real interest rate declines, which stimulates domestic demand. LC and NLC consumption increase, but the increase is more pronounced for LC households. This resonates with previous findings in the literature that more financially constrained households have a higher marginal propensity to consume (Baker and Yannelis 2017; Blundell et al. 2006; Johnson et al. 2006; Zeldes 1989).

The wage share declines on impact due to the only moderate increase in real wages and the delayed response of hours worked. The delay in wage adjustment is driven by the estimated strong realwage inertia and leads initially to an increase in the profit share. The net income share of LC households relative to GDP declines initially with the decline in the wage share. The response of the LC income share turns positive in the medium term. In contrast, the response of the net income share of NLC households does not turn positive after the initial decline, but reverts to baseline in the medium term. 
The fact that both LC and NLC household disposable income relative to GDP decline in Figure 2 relates to the role of fiscal policy. While NLC households suffer from a decline in the wage share and benefit from a higher profit share (dividend payments) on impact, they are, in addition, exposed to falling interest income on short-term bonds and a declining share of government transfers in income (automatic stabilizers). The mirror image of falling household income to GDP is due to an increase in the government budget balance in the model.

\subsection{Quantitative easing}

The purchase of long-term government debt by the central bank reduces the amount of long-term debt held by NLC households. In light of the preference of NLC households for a maturity mix, the price of long-term bonds rises, and the expected return on long-term bonds consequently falls. The decline in the expected return on long-term bonds leads to portfolio rebalancing towards corporate equity and foreign assets, leading to higher investment and real effective depreciation of the domestic currency. The lower expected return on long-term bonds also reduces private savings, which leads to an increase in NLC consumption. Stronger domestic demand increases the demand for labor, which strengthens LC wage income and consumption. Stronger domestic demand and net exports imply an increase in real GDP and higher (demand-driven) inflation.

Figure 1 shows an initial fall in the wage share to GDP. The wage share response turns positive in the medium term, however, as employment and real wages increase. The net income share of LC households declines on impact, but improves in the medium term in line with the wage share. The NLC net income share faces a persistent decline, which is driven primarily by lower income (coupon payments) on long-term bond holdings, as part of the stock is purchased by the central bank in return for interest-free money. The return on short-term bonds remains unchanged in the short run due to the ZLB constraint, but increases in the medium term as the (shadow) interest rate endogenously exits the constraint and becomes positive.

\subsection{Income and wealth inequality}

A metric to assess the impact of shocks on income inequality more directly is the per-capita disposable income of LC and NLC households relative to the average per-capita disposable income in the economy. Figure 3 shows the responses of the relative LC (NLC) net disposable income, i.e., LC (NLC) per-capita disposable income relative to the population average, for the conventional monetary policy and QE shocks in Figures 1 and 2. Both shocks have qualitatively identical effects. The LC disposable income in relative terms slightly declines on impact, but then increases quickly 
to above baseline and persistently remains above baseline in the medium and longer run. The NLC net income in relative terms increases slightly on impact, but then falls below baseline and persistently remains below baseline in the medium and longer run. ${ }^{9}$

\section{Figure 3: Dynamic of disposable household income relative to the economy-wide average}

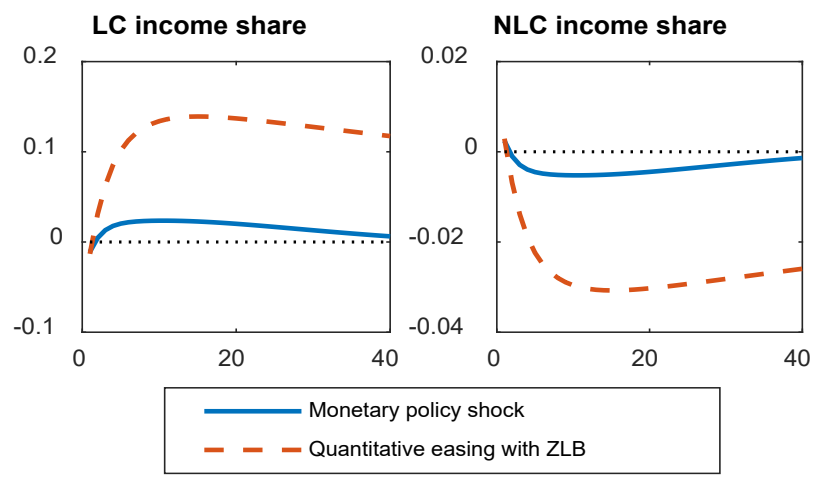

Note: Time intervals on the $\mathrm{x}$-axis are quarters. The income shares measure the respective household (LC vs NLC) disposable income (after taxes and transfers) relative to the economy-wide average household disposable income and are expressed in percentage-point deviations from the baseline.

The relative income responses are driven by the response of wage income versus income on financial assets. Higher employment and real wages in response to expansionary monetary policy lead to higher labor income. Higher labor income benefits especially the LC households, given that wages are their only source of primary revenue. NLC households also receive higher wage income, but at the same time see the contribution of dividend payments and income on financial investment decline in relative terms (Figure 2). In the case of the conventional monetary policy shock, interest income from holding short-term government bonds declines. In the case of the QE shock, NLC households face a decline in their long-term bond position, which implies a loss in income from coupon payments. For monetary policy shocks with similar initial impact on aggregate GDP, the loss of coupon payments $(\mathrm{QE})$ is quantitatively more important than the decline in interest received on short-term bonds (conventional policy shock), which explains the larger changes in the LC versus NLC income shares in the case of QE. For a QE shock that generates around $0.1 \%$ initial increase in real GDP, a change in relative per-capita income by more than 0.1 percentage points for

\footnotetext{
${ }^{9}$ Changes in LC and NLC income relative to the average household income in the economy move, by definition, in opposite directions. The LC versus NLC percentage-point changes differ, however. NLC households represent a larger share of the population according to our estimates. A given absolute change in income therefore implies a more pronounced change in average LC household income compared to average NLC household income. LC and NLC income effects add up to zero when adjusted for LC and NLC population shares.
} 
LC households is not negligible in quantitative terms. The relative income effect for a comparable expansionary shock to the short-term rate (Taylor rule) is much smaller instead.

The relative income responses for LC and NLC households are in line with the finding in Ampudia et al. (2018) for the EA that expansionary monetary policy reduces household income inequality and that positive employment and wage responses are an important driver of this result.

\subsection{Discussion}

Given our two-household model setup with NLC asset-owner versus zero-asset LC households, any increase (decline) in the NLC portfolio value corresponds to increasing (declining) wealth inequality. The expansionary monetary policy shocks raise the value of financial assets on impact, so that the net asset position of NLC households increases in terms of domestic GDP. The valuation effect in response to the conventional monetary policy shock remains temporary and recedes as the monetary shock decays. The effect is not negligible in quantitative terms, however.

The short-term response of NLC wealth to the QE shock is quantitatively very similar to the response to conventional monetary policy shocks. Instead of returning to baseline, however, the net wealth of NLC households falls below baseline in the medium and long term in response to the QE shock. The negative wealth effect derives from the loss of coupon payments, which is a consequence of the NLC households' reduced holding of long-term bonds. The persistent fall in bond returns (coupon payments) leads to a decumulation of NLC assets compared to baseline in the medium and longer term. Overall, the impulse responses suggest that temporary expansionary conventional monetary policy and QE shocks may reinforce wealth inequality temporarily on impact, without implying persistent increases in wealth inequality between asset owners and households without (liquid) assets.

\subsection{Actual volumes of quantitative easing}

Since the model does not lead to transition to a new steady state for real variables in response to temporary monetary policy shocks, changes in income shares and inequality are temporary and decay in the long term. To illustrate the impact of QE volumes on the magnitude of the ECB program over the medium term, we conduct a deterministic experiment where we replicate the path of bond purchases by the central bank in the context of the PSPP.

Figure 4 illustrates the implied path of the QE policy considered. The deterministic shock lasts for three years. It has a hump-shaped pattern due to the AR(2) specification and a cumulative size of 
around 50\% of annual EA GDP. While the expansion of the central bank's balance sheet stops after four years, it remains extended for a long time, given the persistence in the shock profile.

Figure 4: Simulated path of QE program

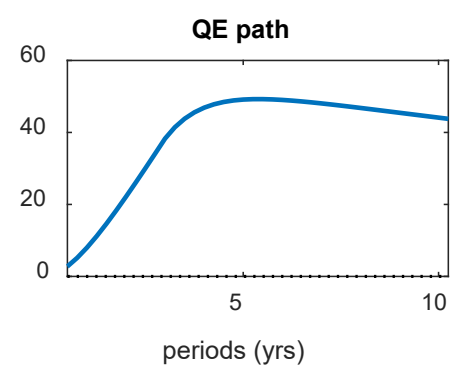

Note: Time intervals on the $\mathrm{x}$-axis are years; units on the y-axis are per cent of GDP.

Figure 5 shows the impact of the policy path on a selection of endogenous model variables. Given the deterministic setting, shock duration and size are known ex ante, i.e., they are anticipated by the private sector.

The effect on GDP is large and reflects the large volume of the QE program as well as its deterministic nature in the scenario. Since the assumption of perfect foresight implies front-loading of the QE effects, real GDP and consumer prices increase by 2\% and 1.2\% on impact, respectively. The effects of the implied QE path are persistent, with real GDP being $0.3 \%$ and consumer prices $6 \%$ above baseline after 10 years.

The impact on LC income as a share of GDP is positive in the medium run, in line with the mediumterm increase in the wage share, and reaches a size of $0.3 \%$ of nominal GDP compared to baseline after 10 years. NLC income to GDP falls, reaching a level of -1.2 percentage points below baseline after 10 years. The asset position of NLC households increases by $20 \%$ of nominal GDP on impact, but falls thereafter to less than 20 percentage points below baseline after 10 years. Both LC and NLC consumption increase in line with higher income. LC consumption rises more in per-cent terms, in line with the increasing LC income-to-GDP share. 


\section{Figure 5: Impact of the deterministic QE path}

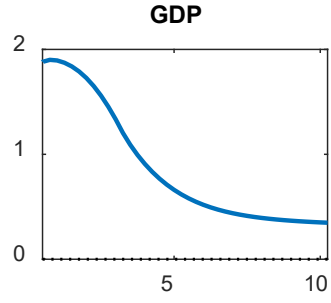

periods (yrs)

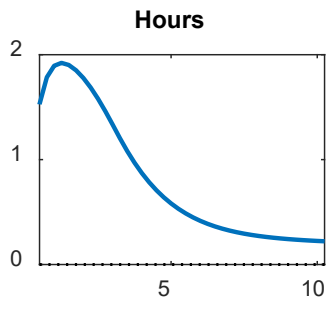

periods (yrs)

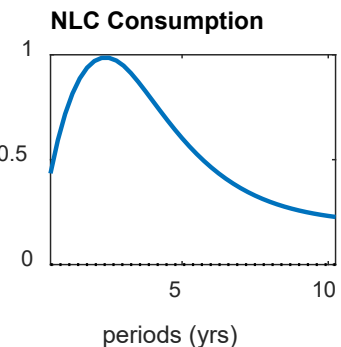

Consumption price

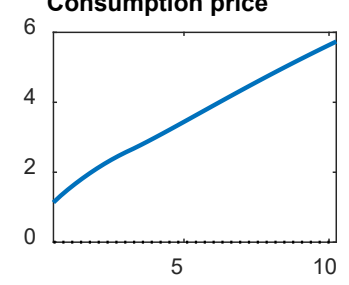

periods (yrs)

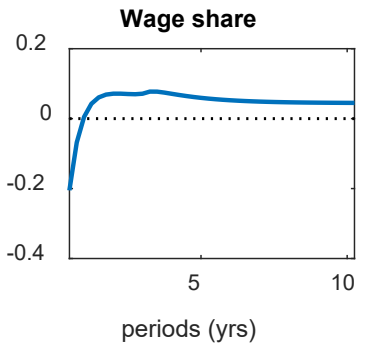

LC Net income share

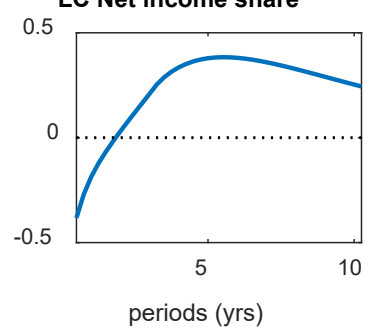

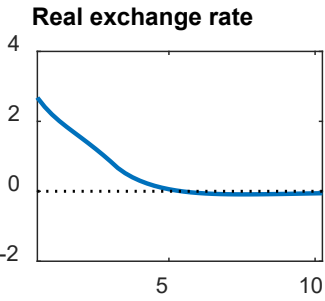

periods (yrs)
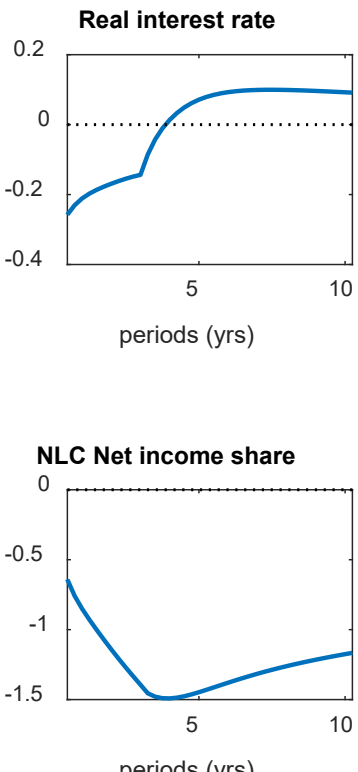

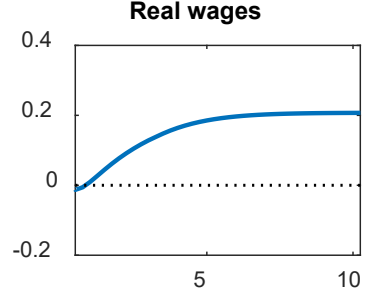

periods (yrs)
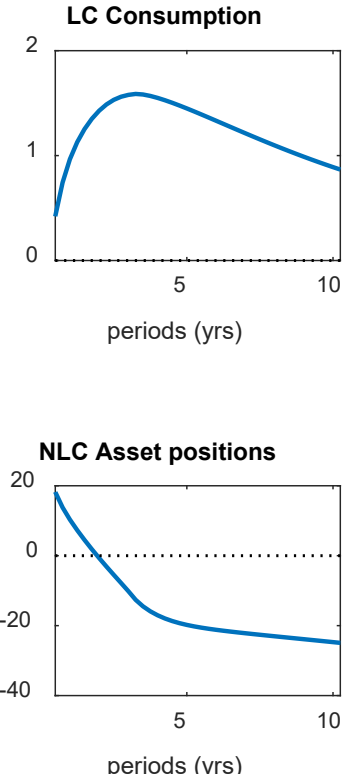

Note: Time intervals on the $\mathrm{x}$-axis are years; units on the $\mathrm{y}$-axis are in per cent (percentage points for inflation, interest rates, income shares, and the asset position to GDP). Shares are expressed in per cent of annual nominal GDP.

\section{Conclusion}

This paper analyzes the distributional consequences of conventional monetary policy and QE using an estimated open-economy DSGE model of the EA and the RoW, with NLC (asset owners) and LC ("hand-to-mouth") households. The model includes imperfect substitutability between government bonds of different maturities and central bank balance sheet operations, and it compares impulse response functions from shocks to the Taylor rule (conventional monetary policy) and the central bank balance sheet $(\mathrm{QE})$.

Overall, expansionary conventional monetary policy and QE shocks do not increase, but rather mitigate income and wealth inequality between population groups in our two-household model in the short (income) and medium (income and wealth) term. While the distinction between two household groups is certainly simplistic, it provides insight with respect to the functional income 
distribution and the dependence of income and wealth effects on income sources and financial market participation.

\section{References}

Adam, K., Tzamourani, P., 2016. Distributional consequences of asset price inflation in the euro area. European Economic Review, 89, 172-192.

Altunbas, Y., Gambacorta, L., Marques-Ibanez, D., 2014. Does monetary policy affect bank risk? International Journal of Central Banking, 10(1), 95-136.

Ampudia, M., Georgarakos, D., Slacalek, J., Tristani, O., Vermeulen, Ph., Violante, G., 2018. Monetary policy and household inequality. European Central Bank Working Paper Series 2170.

Andrés, J., López-Salido, D., Nelson, E., 2004. Tobin's imperfect asset substitution in optimizing general equilibrium. Journal of Money, Credit and Banking, 36, 665-690.

Angeloni, I., Faia, E., Lo Duca, M., 2015. Monetary policy and risk taking. Journal of Economic Dynamics and Control, 52, 285-307.

Baker, S., Yannelis, C., 2017. Income changes and consumption: Evidence from the 2013 federal government shutdown. Review of Economic Dynamics, 23, 99-124.

Bekaert, G., Hoerova, M., Lo Duca, M., 2013. Risk, uncertainty and monetary policy. Journal of Monetary Economics, 60, 771-788.

Blundell, R., Pistaferri, L., Preston, I., 2006. Consumption inequality and partial insurance. American Economic Review, 98, 1887-1921.

Borio, C., Zhu, H., 2012. Capital regulation, risk-taking and monetary policy: A missing link in the transmission mechanism? Journal of Financial Stability, 8(4), 236-251.

Boubaker, S., Gounopoulos, D., Ngyuen, D., Paltalidis, N., 2018. Reprint of: Assessing the effects of unconventional monetary policy and low interest rates on pension fund risk incentives. Journal of Banking and Finance, 92, 340-357.

Casiraghi, M., Gaiotti, E., Rodano, L., Secchi, A., 2018. A “reverse Robin Hood”? The distributional implications of non-standard monetary policy for Italian households. Journal of International Money and Finance, 85, 215-235.

Chen, H., Cúrdia, V., Ferrero, A., 2012. The macroeconomic effects of large-scale asset purchase programmes. Economic Journal, 122(564), 289-315. 
Coibion, O., Gorodnichenko, Y., Kueng, L., Silvia, J., 2017. Innocent bystanders? Monetary policy and inequality. Journal of Monetary Economics, 88, 70-89.

Debortoli, D., Galì, J., 2018. Monetary policy with heterogeneous agents: Insights from TANK models. Mimeo.

de Groot, O. (2014). The risk channel of monetary policy. International Journal of Central Banking, 10 (2), 115-160.

Delis, M., Kouretas, G., 2011. Interest rates and bank risk-taking. Journal of Banking and Finance, 35 (4), 840-855.

Doepke, M., Schneider, M., 2006. Inflation and the redistribution of nominal wealth. Journal of Political Economy, 114(6), 1069-1097.

Dolado, J., Motyovszki, G., Pappa, E., 2018. Monetary policy and inequality under labor market frictions and capital-skill complementarity. CEPR Discussion Papers 12734.

Domanski, D., Scatigna, M., and Zabai, A., 2016. Wealth inequality and monetary policy. BIS Quarterly Review, March 2016, Bank for International Settlements, Basel.

Furceri, D., Loungani, P., Zdzienicka, A., 2018. The effects of monetary policy shocks on inequality, Journal of International Money and Finance, 85(C), 168-186.

Galí, J., López-Salido, D., Vallés, J. 2007. Understanding the effects of government spending on consumption, Journal of the European Economic Association, 5(1), 227-270.

Gertler, M., Karadi, P., 2011. A model of unconventional monetary policy. Journal of Monetary Economics, 58, 17-34.

Giovannini, M., Ratto, M., 2018. Latent variables and real-time forecasting in DSGE models with occasionally binding constraints: Can non-linearity improve our understanding of the Great Recession? Mimeo.

Gornemann, N., Kuester, K., Nakajima, M., 2016. Doves for the rich, hawks for the poor? Distributional consequences of monetary policy. Board of Governors of the Federal Reserve System International Finance Discussion Papers 1167.

Greenwood, R., Vayanos, D., 2014. Bond supply and excess bond returns. Review of Financial Studies, 27, 663-713. 
Guerello, C., 2018. Conventional and unconventional monetary policy vs. households' income distribution: An empirical analysis for the euro area. Journal of International Money and Finance, $85,187-214$.

Guerrieri, L., Iacoviello, M., 2015. OccBin: A toolkit for solving dynamic models with occasionally binding constraints easily. Journal of Monetary Economics, 70, 22-38.

Jimenez, G., Ongena, S., Peydro, J., Saurina, J., 2014. Hazardous times for monetary policy:

What do twenty-three million bank loans say about the effects of monetary policy on credit risktaking? Econometrica, 82 (2), 463-505.

Harrison, R., 2012. Asset purchase policies and portfolio balance effects: A DSGE analysis. In: Chadha, J., Holly, S. (ed). Interest Rates, Prices and Liquidity: Lessons from the Financial Crisis, Cambridge University Press, Cambridge, 117-143.

Hohberger, S., Priftis, R., Vogel, L., 2018. The macroeconomic effects of quantitative easing in the euro area: Evidence from an estimated DSGE model. Bank of Canada Staff Working Papers 18-11.

Iacoviello, M., 2005. House prices, borrowing constraints, and monetary policy in the business cycle. American Economic Review, 95(3), 739-764.

Johnson, D., Parker, J., Souleles, N., 2006. Household expenditure and the income tax rebates of 2001. American Economic Review, 96, 1589-1610.

Kaplan, G., Violante, G., Weidner, J., 2014. The wealthy hand-to-mouth. Brookings Papers on Economic Activity, 45, 77-153.

Kaplan, G., Moll, B., Violante, G., 2018. Monetary policy according to HANK. American Economic Review, 108, 697-743.

Lutz, C., 2015. The impact of conventional and unconventional monetary policy on investor sentiment. Journal of Banking and Finance, 61, 89-105.

Maddaloni, A., Peydro, J., 2011. Bank risk-taking, securitization, supervision, and low interest rates: Evidence from the Euro-area and the U.S. lending standards. Review of Financial Studies, 24 (6), 2121-2165.

Montecino, J., Epstein, G., 2015. Did quantitative easing increase income inequality? Institute for New Economic Thinking Working Papers 28. 
Mumtaz, H., Theophilopoulou, A., 2017. The impact of monetary policy on inequality in the UK: An empirical analysis. European Economic Review, 98, 410-423.

Neal, R. 2003. Slice sampling, The Annals of Statistics, 31(3), 705-767.

Neely, C., 2015. Unconventional monetary policy had large international effects. Journal of Banking and Finance, 52, 101-111.

Neuenkirch, M., Noeckel, M., 2018. The risk-taking channel of monetary policy transmission in the euro area. Journal of Banking and Finance, 93, 71-91.

O’Farrell, R., Rawdanowicz, L., Inaba, K., 2017. Monetary policy and inequality. International Finance, 20, 174-188.

Priftis, R., Vogel, L., 2016. The portfolio balance mechanism and QE in the euro area. Manchester School, 84, 84-105.

Rajan, R., 2006. Has finance made the world riskier? European Financial Management, 12(4), 499-533.

Ricci, O., 2015. The impact of monetary policy announcements on the stock price of large European banks during the financial crisis. Journal of Banking and Finance, 52(C), 245-255.

Saiki, A., Frost, J., 2014. Does unconventional monetary policy affect inequality? Evidence from Japan. Applied Economics, 46, 4445-4454.

Schmitt-Grohé, S., Uribe, M., 2003. Closing small open economy models. Journal of International Economics, 61, 163-185.

Vayanos, D., Vila, J., 2009. A preferred-habitat model of the term structure of interest rates. NBER Working Papers 15487.

Williamson, S. 2009. Monetary policy and distribution. Journal of Monetary Economics, 55(6), 1038-1053.

Woodford, M., 2001. Fiscal requirements for price stability. Journal of Money, Credit and Banking, 33, 669-728.

Zeldes, S., 1989. Consumption and liquidity constraints: An empirical investigation. Journal of Political Economy, 97, 1469-1513. 


\section{APPENDIX A: DATA}

\section{Data sources}

Data for the EA (quarterly national accounts, fiscal aggregates, quarterly interest and exchange rates) are taken from Eurostat. RoW series are constructed on the basis of the IMF International Financial Statistics (IFS) and World Economic Outlook (WEO) databases.

\section{Constructing data series for RoW variables}

Series for GDP and prices in the RoW starting in 1999 are constructed on the basis of data for the following 59 countries: Albania, Algeria, Argentina, Armenia, Australia, Azerbaijan, Belarus, Brazil, Bulgaria, Canada, Chile, China, Colombia, Croatia, Czech Republic, Denmark, Egypt, Georgia, Hong Kong, Hungary, Iceland, India, Indonesia, Iran, Israel, Japan, Jordan, Korea, Lebanon, Libya, FYR Macedonia, Malaysia, Mexico, Moldova, Montenegro, Morocco, New Zealand, Nigeria, Norway, Philippines, Poland, Romania, Russia, Saudi Arabia, Serbia, Singapore, South Africa, Sweden, Switzerland, Syria, Taiwan, Thailand, Tunisia, Turkey, Ukraine, United Arab Emirates, United Kingdom, United States, and Venezuela.

\section{List of observables}

The estimation uses the following time series for the EA: GDP, GDP deflator, population, total employment, employment rate, relative prices with respect to GDP deflator (VAT-consumption, government consumption, private investment, exports, and imports), government investment price relative to private investment, nominal policy rate, and nominal shares of GDP (consumption, government consumption, investment, government investment, government interest payments, transfers, public debt, wage bill, and exports). The list of observables also includes the oil price and the effective exchange rate of the EA. For the RoW we use data on population, GDP, GDP deflator, and the nominal policy rate. The EA-specific QE observables are securities held for monetary policy purposes as proxy for long-term bond holdings by the ECB and the share of long-term debt in total government debt. Furthermore, we use current and 3-month-ahead swap rates on 10-year government bonds to calculate the implied expected period-on-period return on long-term bonds. 
APPENDIX B: CALIBRATION AND POSTERIOR ESTIMATES

\section{Table B.1: Calibrated parameters and steady-state ratios.}

\begin{tabular}{|c|c|c|}
\hline Description & Parameter or ratio & Source \\
\hline Intertemporal discount factor & 0.9975 & annual discount rate of $1 \%$ \\
\hline Degree of openness & 0.19 & data \\
\hline Substitutability btw domestic varieties & 6.97 & endogenized in steady state \\
\hline Weight of disutility of labor & 9.75 & endogenized in steady state \\
\hline \multicolumn{3}{|l|}{ Production } \\
\hline Cobb-Douglas labor share & 0.65 & standard share in literature \\
\hline Depreciation of private and public capital & 0.0144 & data \\
\hline Share of oil in total output & 0.015 & data \\
\hline \multicolumn{3}{|l|}{ Fiscal policy } \\
\hline Consumption tax & 0.20 & data \\
\hline Corporate profit tax & 0.30 & data \\
\hline Labor tax & 0.44 & endogenized in steady state \\
\hline Deficit target & 0.021 & data \\
\hline Debt target & 2.96 & data \\
\hline \multicolumn{3}{|l|}{ Steady-state ratios } \\
\hline Private consumption share & 0.56 & data \\
\hline Private investment share & 0.18 & data \\
\hline Gov't consumption share & 0.20 & data \\
\hline Gov't investment share & 0.03 & data \\
\hline Transfers share & 0.16 & data \\
\hline \multicolumn{3}{|l|}{ Others } \\
\hline Size of the country (\% of world) & 16.44 & data \\
\hline Trend of total factor productivity & 0.0033 & data \\
\hline
\end{tabular}


Table B.2: Prior and posterior distributions of key estimated EA model parameters.

\begin{tabular}{|c|c|c|c|}
\hline \multirow[t]{2}{*}{ Description } & \multicolumn{2}{|c|}{ Prior distribution } & \multirow{2}{*}{$\begin{array}{c}\text { Posterior distribution } \\
\text { Mode (Std.) }\end{array}$} \\
\hline & Dist. & Mean (Std.) & \\
\hline \multicolumn{4}{|l|}{ Preferences } \\
\hline Consumption habit persistence & B & $0.5(0.20)$ & $0.90(0.02)$ \\
\hline Risk aversion & G & $1.5(0.20)$ & $1.54(0.17)$ \\
\hline Inverse Frisch elasticity of labor supply & G & $2.5(0.50)$ & $2.09(0.44)$ \\
\hline Import price elasticity & G & $2(1)$ & $2.54(0.28)$ \\
\hline Steady-state consumption share of NLC HH & $\mathrm{B}$ & $0.65(0.10)$ & $0.82(0.04)$ \\
\hline \multicolumn{4}{|l|}{ Nominal and real frictions } \\
\hline Portfolio adjustment costs & G & $0.0015(0.0006)$ & $0.0007(0.0002)$ \\
\hline Price adjustment cost & G & $60(40)$ & $42.6(9.25)$ \\
\hline Nominal wage adj. cost & G & $5(2)$ & $5.55(1.48)$ \\
\hline Real wage rigidity & $\mathrm{B}$ & $0.5(0.20)$ & $0.97(0.01)$ \\
\hline \multicolumn{4}{|l|}{ Monetary policy } \\
\hline Interest rate persistence & $\mathrm{B}$ & $0.7(0.12)$ & $0.80(0.03)$ \\
\hline Response to inflation & $\mathrm{B}$ & $2(0.4)$ & $1.61(0.19)$ \\
\hline Response to GDP & $\mathrm{B}$ & $0.5(0.2)$ & $0.06(0.02)$ \\
\hline \multicolumn{4}{|l|}{ Autocorrelations of shocks } \\
\hline QE AR(1) (purchases of long-term bonds) & $\mathrm{N}$ & $1.8(0.4)$ & $1.75(0.10)$ \\
\hline QE AR(2) (purchases of long-term bonds) & $\mathrm{N}$ & $-0.8(0.3)$ & $-0.76(0.09)$ \\
\hline Bond risk premium & B & $0.5(0.20)$ & $0.87(0.05)$ \\
\hline Domestic price markup & $\mathrm{B}$ & $0.5(0.20)$ & $0.54(0.13)$ \\
\hline \multicolumn{4}{|l|}{ Standard deviations (\%) of innovations } \\
\hline Monetary policy & $\mathrm{B}$ & $1(0.40)$ & $0.10(0.01)$ \\
\hline QE (purchases of long-term bonds) & $\mathrm{G}$ & $1(0.40)$ & $1.12(0.17)$ \\
\hline Investment risk premium & G & $0.1(0.40)$ & $0.30(0.05)$ \\
\hline Bond risk premium & G & $1(0.40)$ & $0.17(0.09)$ \\
\hline Domestic price mark-up & $\mathrm{G}$ & $2(0.80)$ & $4.46(1.07)$ \\
\hline
\end{tabular}

Notes: Cols. (1) lists estimated model parameters and shocks. Cols. (2)-(3) indicates the prior distribution function (B:

Beta distribution; G: Gamma distribution; N: Normal distribution). Cols. (4)-(5) show the mode and the standard deviation (std) of the posterior distributions of EA parameters. 